\title{
Uncontrolled hypertension secondary to leukemic cell infiltration of kidneys in a hemodialysis patient
}

This article was published in the following Dove Press journal: International Journal of Nephrology and Renovascular Disease 3 June 2010

Number of times this article has been viewed

\author{
Kultigin Turkmen' \\ Lutfullah Altintepe ${ }^{2}$ \\ Ibrahim Guney ${ }^{2}$ \\ Ismet Aydogdu ${ }^{3}$ \\ Osman $\mathrm{Koc}^{4}$ \\ Mehmet Ali Erkut ${ }^{5}$ \\ Halil Zeki Tonbul' \\ 'Department of Nephrology, \\ Meram School of Medicine, Selcuk \\ University, ${ }^{2}$ Meram Training and \\ Research Hospital, Selcuk University, \\ ${ }^{3}$ Department of Hematology, Meram \\ School of Medicine, Selcuk University, \\ ${ }^{4}$ Department of Radiology, Meram \\ School of Medicine, Selcuk University, \\ ${ }^{5}$ Department of Hematology, Meram \\ Training and Research Hospital, Selcuk \\ University
}

Correspondence: Kultigin Turkmen Selcuk Universitesi Meram Tip Fakultesi Hemodiyaliz Sekreterligi, Meram, 42090, Konya/Turkey

Tel +90 332223648 I

Fax +90 332 2237I 21

Email mdkt20I0@yahoo.com

\begin{abstract}
Leukemic infiltration of the kidney is usually silent, and the admission of the patients with renal dysfunction or acute kidney injury is uncommon. We present a 34-year old hemodialysis patient with new onset of uncontrolled hypertension, erythropoietin-resistant anemia, thrombocytopenia, and Bell's palsy. On admission, his blood pressure (BP) was 210/110 mmHg and he had petechiae and purpura at upper and lower extremities. Renal ultrasonography (USG) showed bilaterally enlarged kidneys without hydronephrosis, unlike his previous USG, which determined bilaterally atrophic kidneys. Acute lymphoblastic leukemia, hypertensive crisis due to bilateral leukemic cell infiltration of kidneys, tumor lysis syndrome, and leukemic involvement of the facial nerve were diagnosed. Despite intense antihypertensive management, his BP was not controlled. After prednisolone, daunorubicine, and vincristine therapy, the size of kidneys diminished and his BP dropped under normal range. In conclusion, pathological findings such as uncontrolled hypertension, flank pain, skin rashes, and abnormal blood count should be considered carefully, even in patients with end-stage renal disease receiving renal replacement therapy.
\end{abstract}

Keywords: leukemic cell infiltration, uncontrolled hypertension, hemodialysis

\section{Introduction}

Acute lymphoblastic leukemia (ALL), while frequently diagnosed in children, can also be seen in adulthood. Patients with T-cell ALL and the M4 and M5 subtypes of acute myeloblastic leukemia are at a higher risk for extramedullary disease, including renal parenchymal involvement, which is the most frequent extramedullary metastatic site. ${ }^{1}$ Consequences of leukemic infiltration of the kidneys are asymptomatic bilateral renal enlargement, acute renal failure, and/or secondary hypertension, as reported previously. We report a patient with end-stage renal disease (ESRD), receiving hemodialysis, and uncontrolled hypertension due to leukemic cell infiltration of the kidneys.

\section{Case}

A 34-year-old man who had ESRD was admitted to the emergency room with complaints of productive coughing, shortness of breath, and hypertension not controlled by his previous antihypertensive medication. He had been receiving hemodialysis three times weekly for 2 years. The etiology of his kidney disease could not be determined. He did not have diabetes or dyslipidemia. He had a history of generalized seizures and had used carbamazepine for 15 years. Despite iron supplementation and erythropoetinstimulating agent therapy, he had normochrome-normocytic anemia. His blood pressure (BP) was under control with ramipril $5 \mathrm{mg}$ once daily and amlodipin $5 \mathrm{mg}$ once daily. Before admission, he also had had peripheral facial nerve palsy (Bell's palsy) and was 
treated with corticosteroid therapy for 3 weeks. On admission, he seemed pale, dyspneic, and agitated. His blood pressure was $210 / 110 \mathrm{mmHg}$. His heart rate was regular at $98 \mathrm{bpm}$, He was afebrile and had a 2/6 systolic ejection murmur on auscultation. He had crackles at the bases of the lungs and +/+ pedal edema bilaterally. There was not any audible bruit from the abdominal aorta and renal arteries. Bilateral upper and lower extremity arteries were palpable. He had petechiae and purpura at upper and lower extremities. His urine output was $500 \mathrm{~mL} /$ day.

The initial biochemistry and complete blood counts of the patient are shown in Table 1. Urinalysis revealed trace protein, and no red blood cells per high-power field. There was no active urinary sediment. 24-hour urine protein was $1 \mathrm{~g}$. Anti-nuclear antibody, Anti-ENA, ANCA, and cryoglobulins were negative, and $\mathrm{C} 3$ and $\mathrm{C} 4$ levels were normal. Hepatitis B surface antigen, anti-HBs, Anti-HAV, and Anti-HCV were also negative. His previous ultrasonography (USG) revealed bilaterally diminished kidney sizes (the right kidney measured $90 \times 40 \mathrm{~mm}$, and the left kidney measured $85 \times 45 \mathrm{~mm})$. On a blood smear, atypical lymphocytes were seen, and bone marrow biopsy showed hypercellularity, with cells containing minimal cytoplasm and abnormal nuclear-cytoplasmic ratio. Flow cytometric studies of bone marrow tissues showed a population of T-cells that expressed CD2, CD3, CD4, CD5, CD7, and cytoplasmic CD3. These findings were consistent with precursor T-cell ALL. Despite the combination of 5 different classes of antihypertensive therapy (ramipril

Table I Initial laboratory parameters of the patient

\begin{tabular}{|c|c|c|}
\hline Parameter & Value & Normal range \\
\hline White blood cell count (cells $/ \mathrm{mm}^{3}$ ) & 20,700 & $4,000-10,000$ \\
\hline Neutrophils (cells/mm³) & 6,400 & $2,500-7,500$ \\
\hline Basophils (cells/mm³) & 100 & $0-200$ \\
\hline Lymphocytes (cells/mm³) & 12,500 & $\mathrm{I}, 500-3,500$ \\
\hline Monocytes (cells/mm³) & $\mathrm{I}, 200$ & $200-900$ \\
\hline Eosinophils (cells $/ \mathrm{mm}^{3}$ ) & 600 & $200-600$ \\
\hline Hemoglobin (g/dL) & 8.6 & $12-14$ \\
\hline Mean corpuscular volume & 89 & $80-96$ \\
\hline Platelets (cells $/ \mathrm{mm}^{3}$ ) & 10,000 & $150,000-400,000$ \\
\hline Urea (mg/dL) & 90 & $17-43$ \\
\hline Creatinine (mg/dL) & 7.6 & $0.4-1.0$ \\
\hline Sodium (mEq/L) & 139 & $135-145$ \\
\hline Potassium (mEq/L) & 4.3 & $3.5-5.5$ \\
\hline Uric acid (mg/dL) & 15.5 & $3.5-7.2$ \\
\hline Lactate dehydrogenase $(\mathrm{mg} / \mathrm{dL})$ & 990 & $98-192$ \\
\hline Albumin $(g / d L)$ & 3.4 & $4.0-5.5$ \\
\hline Iron $(\mu g / d L)$ & 117 & $50-170$ \\
\hline TIBC ( $\mu g / d L)$ & 108 & $255-450$ \\
\hline Ferritine $(\mathrm{ng} / \mathrm{mL})$ & $\mathrm{I}, 325$ & $15-200$ \\
\hline
\end{tabular}

Abbreviation: TIBC, total iron binding capacity.
$10 \mathrm{mg} /$ day, losartan $100 \mathrm{mg} /$ day, amlodipin $10 \mathrm{mg} /$ day, doxazosin $4 \mathrm{mg} / \mathrm{day}$, and intravenous nitroglycerin), and aquate hemodialysis, his blood pressure did not drop under 180/110 mmHg. To establish the diagnosis, we performed abdominal computed tomography (CT), which showed bilaterally enlarged kidneys (Figure 1). We consulted over the patient with a hematologist and initiated peripheral vascular disease (PVD) chemotherapy (daunorubicine $45 \mathrm{mg} / \mathrm{m}^{2}$ per day for 7 days, vincristine $2 \mathrm{mg} / \mathrm{m}^{2}$ per day for 7 days, and prednisolone $64 \mathrm{mg} /$ day for 28 days). To treat hyperuricemia, the patient was also given allopurinol and alkalized fluids, with ongoing hemodialysis. After the first cycle of PVD, his blood pressure dropped under 130/80 $\mathrm{mmHg}$, and the renal USG revealed bilaterally atrophic kidneys. In this case, we hypothesized that ALL can bilaterally infiltrate the kidney in patients with ESRD. Kidney biopsy was considered before chemotherapy, but this procedure could not be performed because of uncontrolled hypertension and severe thrombocytopenia. After the first chemotherapy, his neutrophil counts dropped under $500 / \mathrm{mm}^{3}$, and febrile neutropenia developed. On the following days, despite the appropriate antibiotherapy, he had severe dyspnea and tachypnea. To establish the diagnosis, we performed thoracic CT. Cavitary lesion secondary to aspergillosis was diagnosed. We initiated antifungal

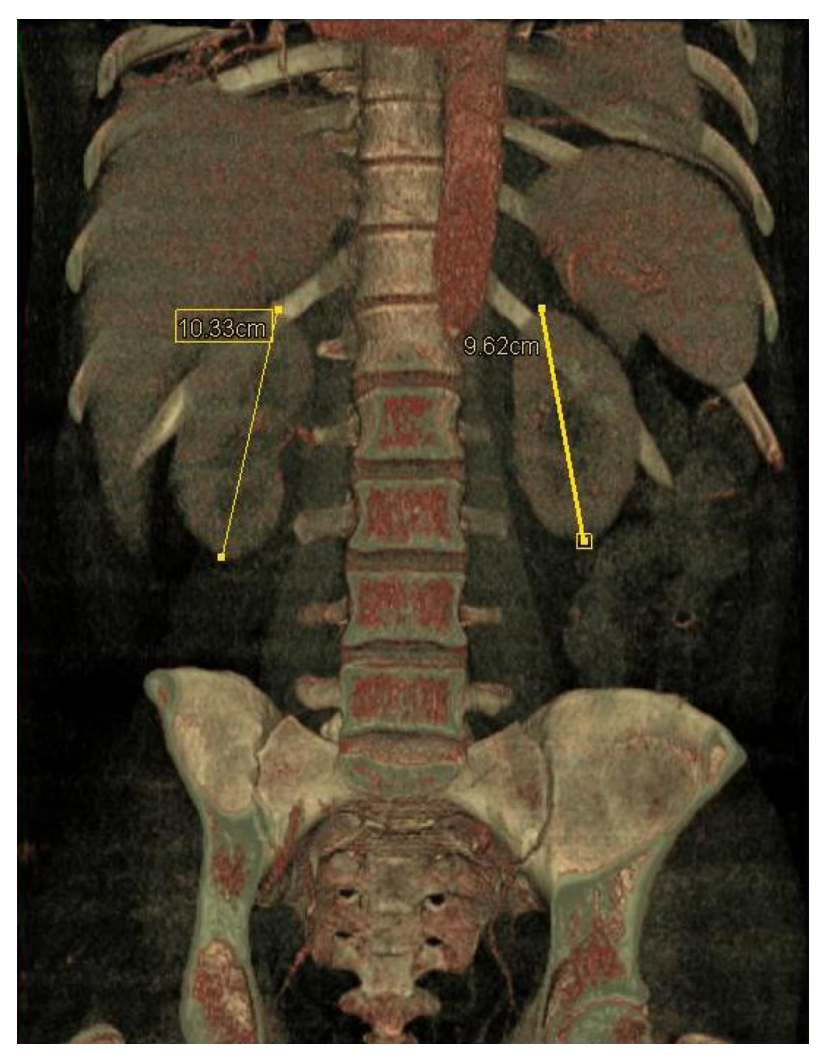

Figure I Abdominal computed-tomography scan showing bilaterally enlarged kidneys. 
therapy and the patient was entubated in an intensive care unit. Despite the intensive therapy, he died secondary to respiratory failure.

\section{Discussion}

ALL is a malignant disorder that orginates from a single B- or T-lymphocyte progenitor. The disease is most common in children but can occur at any age. ALL represents about $12 \%$ of all leukemias diagnosed in United States, and $60 \%$ of all cases occur in patients younger than 20 years. ${ }^{2}$ Leukemic patients who are at a higher risk for extramedullary disease, including renal parencymal involvement, include those with T-cell ALL, as well as those with the M4 and M5 subtypes of acute myelogenous leukemia. ${ }^{1}$ Although ALL and its extramedullary infiltrations can frequently be seen in children, these manifestations have also been reported in adults previously. ${ }^{3}$ The kidneys are the most frequent extramedullary site of leukemic infiltration, which was identified in $63 \%$ of autopsies performed on patients who had died with either lymphoid or myeloid leukemia. ${ }^{4}$ Kidney involvement of leukemic cells might be related to the embryological orgin of hematopoietic organ developments. ${ }^{5}$

We present a hemodialysis patient with new onset of uncontrolled hypertension, ESA-resistant anemia, thrombocytopenia, and Bell's palsy, secondary to ALL. The case presented here is unusual because the patient did not have a previous history of ALL. Leukemic infiltration of the kidney is usually silent, and the hospital admission of patients with renal dysfunctions such as renal enlargement, hematuria, proteinuria, treatmentresistant-hypertension, or acute kidney injury is uncommon. In a German multicenter trial of 938 adult patients with ALL, 10\% of patients had organ infiltration, and only $0.4 \%$ had clinical evidence of renal involvement. ${ }^{6}$ Patients with enlarged kidneys may suffer abdominal fullness or pain. Physical examination reveals a palpable abdominal mass in 3\%-5\% of patients. Multiple reports suggest that enlarged kidneys due to leukemic infiltration, detected by USG, CT, or excretory urography, is the most common imaging manifestation observed in renal involvement of ALL. ${ }^{1}$ Olgar et al showed that renal leukemic infiltration is a risk-factor for developing hypertension, and they also determined that hypertension might be a risk factor for renal parenchymal disease. In that study, hypertension was found in 21 out of 334 (6.3\%) patients with ALL. Therefore, several factors affecting hypertension, such as age, elevated uric acid levels, blood transfusions, and treatment-induced encephalopathy should be considered. ${ }^{8}$ In the present case, he had well-controlled hypertension following treatment with an angiotensin-converting enzyme- (ACE) inhibitor and a calcium channel blocker (CCB). However, after the onset of ALL, the blood pressure of the patient did not drop under 180/100 mmHg with 5 different groups of antihypertensive drugs, including ACE-inhibitor, angiotensin-receptor blocker, $\mathrm{CCB}, \alpha$-blocker, and intravenous nitroglycerin. We also hypothesized that the renin-angiotensin-aldosterone system may be responsible for his therapy-resistant hypertension, due to compression of tubules by leukemic cells. This hypothesis may clarify the treatment-resistant hypertension pathogenesis in the present case. Tumor lysis syndrome (TLS) is another important complication in ALL patients, especially those treated with chemotherapy. This syndrome may lead to both acute uric acid and phosphate nephropathy, which can also progress to acute renal failure. The patient presented had TLS, with increased uric acid and lactate dehyrogenase levels after chemotherapy that also contributed to resistant hypertension due to hyperuricemia.

Interestingly, the patient had Bell's palsy before admission, which also supports leukemic cell infiltration. Prednisolone was given to treat the situation before admission, which could also have contributed to TLS and hypertension in this patient.

The patient presented here also had skin rashes, such as petechiae and dry purpura, when he was first admitted to our medical center. Since bleeding into the skin is one of the most common findings in thrombocytopenia, this part of the examination should be the most detailed. The differential diagnoses of skin rashes in patients with thrombocytopenia vary according to concomitant symptoms and physical examination findings. Sites of bleeding should be noted, especially in the dependent parts of the body. These are normally the feet and ankles in ambulatory patients, but may be the presacral area in bedridden patients. Dry purpura is the term used when the only bleeding is in the skin. Wet purpura means that there is extensive mucous membrane bleeding. It is generally felt that the presence of wet purpura is the more serious, and is a prognostic sign for potentially life-threatening hemorrhage. Although rare, malignancy-associated vasculitis occurs more often with hematologic rather than solid malignancies. The classic presentation is that of a necrotizing leukocytoclastic vasculitis involving the skin, with palpable purpura, typically in dependent areas. ${ }^{9}$ It is hypothesized that tumor-related antigens, or cryoglobulins, form immune complexes, which are then deposited in the skin and result in a vasculitis. It may be especially common in acute myelomonocytic leukemia and precede the clinical onset of the leukemia. Systemic vasculitis in patients with lymphoproliferative disorders (lymphocytic lymphoma, Waldenstrom's macroglobulinemia, or chronic lymphocytic leukemia) is most often caused by 
cryoglobulinemia. ${ }^{9}$ However, our patient did not have other clinical symptoms, such as fever, headache, arthralgia and myalgia, or laboratory findings of vasculitis, such as increased erythrocyte sedimentation rate, ANA, ANCA, cryoglobulins, or hepatitis $\mathrm{B}$ and $\mathrm{C}$.

\section{Conclusion}

In conclusion, pathological findings such as uncontrolled hypertension, flank pain, skin rashes, and abnormal blood count could be a part of a systemic disease or malignany in patients with ESRD who are receiving renal replacement therapy. Although ALL and its extramedullary infiltrations can frequently be seen in children, these manifestations are also reported in adults. Leukemic cell infiltration of the kidneys can cause either renal failure, hypertension, or asymptomatic kidney enlargement. Treatments to be considered for hypertension associated with leukemic cell infiltration should include multiple drug combination, such as antihypertensive agents, chemotherapeutics, and antihyperuricemic agents. Despite the appropriate therapy, management of patients with ALL and ESRD is extremely difficult because of the complications with both the diseases and the medications.

\section{Disclosure}

The authors report no conflicts of interest in this work.

\section{References}

1. Hilmes AM, Dillman RJ, Mody JR, Strouse JP. Pediatric renal leukemia:spectrum of CT imaging findings. Pediatr Radiol. 2008;38: 424-430.

2. Ries LA, Kosary CL, Hankey BF, et al, editors. SEER Cancer Statistics Review 1973-1995. Bethesda, MD: National Cancer Institute; 1998.

3. Suh W, Wainberg ZA, de Vos S, Cohen AH, Kurtz I, Nauyen MK. Acute lymphoblastic leukemia presenting as acute renal failure. Med Princ Pract. 2008;17(6):504-506.

4. Kirshbaum JD, Preuss FA. Leukemia, a clinical and pathological study of 123 fatal cases in a series of 14,400 necropsies. Arch Intern Med. 1943;71:777-792.

5. Ohneda O, Fennie C, Zheng Z, Donahue C, La H, Villacorta R, Cairns B, Lasky LA. Hematopoietic stem cell maintenance and differantation are supported by embryonic aorta-gonad-mesonephros region-derived endothelium. Blood. 1998;92:908-919.

6. Hoelzer D. Acute lymphoblastic leukemia in adults. In: Hoffman R, Benz EJ, Shattil SJ, et al, editors. Hematology: Basic Principles and Practice. New York, NY: Churchill Livingston. 1991; p. 793-804.

7. Lundberg WB, Cadman ED, Finch SC, Capizzi RL. Renal failure secondary to leukemic infiltration of the kidneys. Am J Med. 1977;62:636-642

8. Olgar S, Yetgin S, Cetin M, Aras T. Can renal leukemic infiltration cause hypertension in children? J Pediatr Hematol Oncol. 2006;28:9.

9. Wooten MD, Jasin HE. Vasculitis and lymphoproliferative diseases. Semin Arthritis Rheum. 1996;26:564.

\section{Publish your work in this journal}

The International Journal of Nephrology and Renovascular Disease is an international, peer-reviewed open-access journal focusing on the pathophysiology of the kidney and vascular supply. Epidemiology, screening, diagnosis, and treatment interventions are covered as well as basic science, biochemical and immunological studies. The journal welcomes original research, clinical studies, reviews \& evaluations, expert opinion and commentary, case reports and extended reports. The manuscript management system is completely online and includes a very quick and fair peerreview system, which is all easy to use. Visit http://www.dovepress.com/ testimonials.php to read real quotes from published authors. 